\title{
Toward international primary care reform
}

\author{
Barbara Starfield MD MPH
}

$\infty$ See related research paper by Glazier and colleagues, page E72.

$\mathrm{P}$ rimary care reform is now a worldwide imperative. National health care systems with strong primary care infrastructures have healthier populations, fewer health-related disparities and lower overall costs for health care. ${ }^{1}$ In the World Health Organization's 2008 World Health Report, ${ }^{2}$ all countries were encouraged to orient their health care systems toward strengthened primary care. Such reforms are unlikely to improve overall population health, equalize distribution of health care resources or reduce costs unless they address both the systemic and clinical characteristics of primary care. ${ }^{3}$

To achieve effective primary health care at the systemic level, several evidence-based goals must be met. These include the equitable distribution of resources, progressive and universal financing, low or no copayments and comprehensive coverage. ${ }^{3,4}$ The key components of primary care at the clinical level include access to and use of first-contact care, patient-focused (rather than disease-focused) care over time for defined populations, services that are comprehensive and timely, and coordination of care when patients need services elsewhere.

In this issue of CMAJ, Glazier and colleagues ${ }^{5}$ address models of reimbursement used by physicians. In their welldesigned (but not randomized) study, the authors examined the practice-related characteristics and patterns of care of physician groups in the province of Ontario, comparing those paid under a capitation model of reimbursement with those paid under an enhanced fee-for-service model. Laudably, both models of reimbursement incorporated a number of features that enhance the benefits of primary care. These features included rostering of patients, and financial incentives to provide comprehensive and coordinated care, care for mental illness, after-hours care and preventive care.

In their study, Glazier and colleagues controlled for differences in morbidity levels and demographic characteristics of patients. They found that patients of practice groups that used the capitation model of reimbursement had a lower level of morbidity and were more likely to visit an emergency department with less urgent problems. These differences had almost certainly been present before the capitation model was adopted, however. After adjusting for physician and patient characteristics, the authors found that practice groups using the capitation model provided less after-hours care but their patients had higher rates of visits to emergency departments. Less after-hours care could have led to more continuity of care if after-hours care was more likely to be provided by ro-

\section{Key points}

- To achieve health care systems oriented toward primary care, efforts at reform must address both the systemic and clinical characteristics of primary care.

- The model of physician reimbursement is not related to patient outcomes, although cost may be affected when financial incentives for nonindicated care are included.

- Increases in costs for health care are driven mainly by use of expensive technology and specialist care.

- If health care systems are to become more effective and more equitable, care must become more focused on patients than on disease.

tating physicians rather than the patient's usual primary care provider, whereas greater use of emergency department services would have reduced continuity of care. Because the higher rate of visits to emergency departments was observed only in rural areas, it is not clear whether this finding was a direct result of a trade-off between after-hours and emergency department visits in capitated practices.

The findings of Glazier and colleagues add to other studies in the literature showing that models of reimbursement make little consistent difference in the clinical outcomes of primary care apart from increases in cost that occur when financial incentives are offered for medical interventions. ${ }^{6,7}$ Mode of payment is not associated with the orientation of a health care system toward primary care.

The evaluation by Glazier and colleagues may have been motivated, at least in part, by the cost-related implications of providing after-hours care. Yet increases in costs are due mainly to increases in the use of expensive technology and specialist care rather than to patient characteristics (including the increasing size of the elderly population) ${ }^{8}$ In countries such as the United States, where the health care system is dominated by private, for-profit enterprise, high rates of use of specialists, overuse of unnecessary interventions, unregulated prices, and high administrative costs are the main contributors to increases in overall costs. Had Glazier and colleagues examined the frequency of interventions, rates of referrals and use of specialists by patients of both types of practices, insight might have been gained into the influence of payment mode on the costs of different systemic characteris-

Barbara Starfield is University Distinguished Professor, Johns Hopkins University, Baltimore, Maryland, USA. 
tics and clinical features of primary care practice.

To what extent can new, systemic approaches to reform foster the cardinal features of primary care? Can systemic reform help to make health care financing and the distribution of health care resources more equitable and lower copayments? Some hypotheses can be posed. New approaches to organizing health care services are unlikely to improve care unless they are based on a recognition that care needs to be focused on the patient rather than on the disease. This is true at least in part because rates of comorbidity are rapidly increasing. Evaluative techniques such as those used by Glazier and colleagues represent a large step forward in characterizing comorbidity in individuals and populations. Neither electronic information technology nor large teams of professionals have yet been shown effective in improving primary care. Models of care based on the diagnosis and management of a small set of specific chronic diseases are not likely to have much impact on overall population health or equity in health. Nor is adherence to guidelines for treating such conditions. The evidence on which most such models is based is flawed ${ }^{9}$ and not generalizable to populations in primary care.

In contrast, patient-focused primary care has been shown to be beneficial. The World Health Organization's 2008 report ${ }^{2}$ has documented large improvements in population health and equity in health derived from primary care reform. Notably, middle-income countries such as Brazil and Thailand have expanded financing of health care to provide universal coverage through a network of government-owned health centres mandated to provide comprehensive primary care. Countries with health care systems that have historically been based on a market orientation (e.g., Germany and the Netherlands) are strengthening government regulations to make their health services more equitable and cost-effective. Countries with a long tradition of training general practitioners (e.g., Spain, France, Belgium and Germany) have instituted reforms to encourage long-term patient-practitioner relationships through patient rostering in general practice. Specialist care is provided mainly through referral. Most changes in payment procedures involve mixed methods, with a base of capitation and an added fee-for-service component to encourage more indicated and comprehensive care.

Strong government leadership, buttressed by advocacy for general practice, has been critical in achieving such reforms. ${ }^{10}$ Research and development over the past 20 years has resulted in an understanding of primary care and methods to measure its essential attributes. Any reform that aims to improve population health and eliminate disparities must foster a primary care model, as in Ontario.

\section{Competing interests: None declared.}

\section{REFERENCES}

1. Starfield B, Shi L, Macinko J. Contribution of primary care to health systems and health. Milbank $Q 2005 ; 83: 457-502$.
2. World Health Organization. The world health report 2008: primary health care: now more than ever. Geneva (Switzerland): The Organization; 2008. Available: www.who.int/whr/2008/whr08_en.pdf (accessed 2009 Apr. 17).

3. Starfield B, Shi L. Policy relevant determinants of health: an international perspective. Health Policy 2002;60:201-18.

4. Closing the gap in a generation: health equity through action on the social determinants of health. Final Report of the Commission on Social Determinants of Health. Geneva (Switzerland): World Health Organization; 2008.

5. Glazier RH, Klein-Geltink J, Kopp A, et al. Capitation and enhanced fee-for-service models for primary care reform: a population-based evaluation. CMAJ 2009; 180:E72-E81

6. Gosden T, Forland F, Kristiansen IS, et al. Impact of payment method on behaviour of primary care physicians: a systematic review. J Health Serv Res Policy 2001;6:44-55.

7. Krasnik A, Groenewegen PP, Pedersen PA, et al. Changing remuneration systems effects on activity in general practice. BMJ 1990;300:1698-701.

8. Health Council of Canada. Value for money: making Canadian health care stronger. Toronto (ON): The Council; 2009. Available: www.healthcouncilcanada.ca/docs/rpts /2009/HCC_VFMReport_WEB.pdf (accessed 2009 Mar. 12).

9. Shaneyfelt TM, Centor RM. Reassessment of clinical practice guidelines: Go gently into that good night. JAMA 2009;301:868-9.

10. Gérvas J, Pérez Fernández M. Western European best practice in primary healthcare. Eur J Gen Pract 2006;12:30-3

Correspondence to: Dr. Barbara Starfield, University Distinguished Professor, Johns Hopkins University, Rm. 452, 624 North Broadway, Baltimore MD 21205, USA; fax 410 614-9046; bstarfie@jhsph.edu

\section{Accredited Cannabinoid Education: an Online Program}

\section{Medical Marijuana: an evidence based guide for medical practitioners}

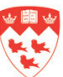

\section{CHPE/FCPS}

From and accredited by the

McGill Center for Continuing Health Professional Education

Thursday, June 4th, 12-1 pm (Live, English)

Thursday, June 11th, 12-1 pm (Live, French)

An archived version will be available anytime after.

Dr. Mark A. Ware, MBBS MRCP MSc

Research Director, McGill University Health Centre Pain Clinic

Executive Director, Canadian Consortium for

the Investigation of Cannabinoids

Credits:

RCPSC Section 1,

CFPC Mainpro-M 1,

AMA PRA Category 1

Supported by unrestricted educational grants

Information: www.ccic.net

Free Registration: http://cme.mcgill.ca/client/register_can.php 